American Journal of Pharmacology and Toxicology 3 (1): 185-192, 2008

ISSN 1557-4962

(C) 2008 Science Publications

\title{
Following the Heart: The History of the J-Curve in Stroke Risk
}

\author{
Shoshana Reshef and Daniel Reshef \\ Department of Epidemiology, Johns Hopkins Bloomberg School of Public Health, \\ Johns Hopkins University, Baltimore, Maryland
}

\begin{abstract}
Reports of a J-shaped relationship between blood pressure and ischemic stroke are rare. The purpose of this study was to trace the published history of the J-curve theory as it relates to blood pressure, ischemic heart disease and eventually ischemic stroke. The J-curve publications on the relationship between Diastolic Blood Pressure (DBP) and ischemic stroke suggest that in certain populations, such as older adults, or hypertensives, a threshold for lowering blood-pressure may exist and may warrant consideration in order to insure adequate cerebral perfusion and stroke prevention. The cerebrovascular mechanisms possibly at play as risk factors for ischemic stroke when DBP is reduced are large and small vessel ischemic disease, reduced baro-receptor reactivity, reduced vasomotor reactivity, and sluggish auto-regulatory mechanism. The optimal diastolic blood-pressure for ischemic stroke-risk reduction ranged between 65 and $85 \mathrm{~mm} \mathrm{Hg}$. DBP levels below (as well as above) that range were associated with increased risk. More studies are needed.
\end{abstract}

Key words: J-curve, stroke, diastolic blood pressure, hypertension, hypertension treatment

\section{INTRODUCTION}

The living body, though it has need of the surrounding environment, is nevertheless relatively independent of it. This independence which the organism has of its external environment derives from the fact that in the living being, the tissues are in fact withdrawn from direct external influences and are protected by a veritable internal environment which is constituted, in particular, by the fluids circulating in the body. Claude Bernard (1813-1878).

Claude Bernard, one of the founders of modern physiology, was the first to recognize that the physiological systems within the body work to maintain a balanced and steady internal environment, the milieu interieur $^{[1]}$, despite external variations. In a commentary entitled the J-curve-is it clinically relevant? S.G. Carruthers $^{[2]}$, from the executive committee of the HOT study, gave credit to Claude Bernard's milieu interieur theory and stated that it is self evident that extremes in blood-pressure, like other physiological parameters, are incompatible with good health. Consequently, a $\mathrm{U}$ or $\mathrm{J}$ shaped relationship must exist between arterial pressure and morbidity or mortality.

Systolic and diastolic pressures were viewed as separate predictors of hypertension for the first time by $\mathrm{MH}^{[3]}$. Since then the interest in the relationships between each of these two blood-pressure indices and the risk for cardiovascular events, such as myocardial infraction and stroke has been on-going. From the 1920's till the mid 1980s, most of the risks associated with hypertension were ascribed to high (as seen among people under age 50) $\mathrm{DBP}^{[4]}$. In the Framingham Heart Study, a gradual shift from diastolic to systolic bloodpressure-in relation to Coronary Heart Disease (CHD) in particular-was noted with the increasing age of the population. Around the same time increasing DBP in people over age 60, was shown to be negatively associated with cardiovascular risk in some studies ${ }^{[5-7]}$.

The purpose of this study review was to trace the development of the J-curve theories explaining relationships between blood pressure and an ischemic cardiovascular outcome. These postulates, initially developed to explain the relationship between low blood pressure and heart disease, were based on epidemiologic findings. Similar theories were eventually developed to explain findings about the relationship between low blood pressure and ischemic stroke.

\section{MATERIALS AND METHODS}

Published prospective and retrospective studies were identified, as well as reviews, editorials and letters to the editor, using a Medline database search with the key words blood pressure, DBP, systolic blood pressure, stroke, cerebrovascular or cardiovascular disease, J-shape, U-shape, J-curve, curvilinear and relationship. References of pertinent publications were scanned for further information. Articles with 
suggestive explanatory mechanisms were selected as well. No date limit was applied. The retrieved information was classified into studies with $\mathrm{J}$-shaped outcome on heart disease, studies with J-shaped outcome on stroke and opinion/hypothesis generating papers. The studies were reported in a chronological order.

The J-Curve phenomenon in this review refers to a curve linear relationship between a blood pressure index and a cardiovascular outcome, whereby the observed outcome decreases initially with decreasing blood-pressure until a threshold is reached beyond which the risk of the outcome begins to increase. When graphed, this relationship resembles a J-shaped line.

\section{RESULTS}

\section{The first J-curves:}

A phenomenon of heart disease: An association between reduction of DBP and cardiac ischemic injury was first suggested by Stewart in $1979^{[8]}$. Following 169 severely hypertensive treated patients for 6 years, he observed a fivefold increase in myocardial infarction among those whose DBP was reduced below $90 \mathrm{~mm}$ Hg compared to people with DBP between 100 and 109 $\mathrm{mm} \mathrm{Hg}$. Stewart's findings challenged the general belief fostered by data from insurance companies ${ }^{[9]}$ (whose clients were usually healthy) that the lower the diastolic pressure the better ${ }^{[10]}$. Stewart's findings were supported by Anderson ${ }^{[11]}$ who re-analyzed data from the Framingham study and found increased cardiovascular events in DBP below $90 \mathrm{~mm} \mathrm{Hg}$.

Stewart's report was largely neglected for about a decade till Cruickshank et al. reported a similar phenomenon in $1987^{[12]}$. Cruickshank-who coined the term J-curve ${ }^{[13]}$ studied 902 hypertensive patients recruited for a treatment clinical trial and followed up to 10 years. Forty fatal myocardial infarctions occurred. Cruickshank was able to segregate the 342 subjects with preexisting coronary artery disease. Only participants with pre-existing coronary heart disease experienced an increased rate of events at the lowest attained DBP (below $85 \mathrm{~mm} \mathrm{Hg}$ ). The optimal DBP level was $85-90 \mathrm{~mm} \mathrm{Hg}$ (mortality rate $=6$ per1000 person year). Mortality rates in the lowest and highest DBP levels respectively were 12 and 17 per 1000 person years. No J-shaped relationship was observed between systolic pressure and cardiovascular events or in subjects without pre-existing ischemic heart disease. The J-shaped effect appeared to be a complication of treatment in people with an already compromised coronary blood flow.
Thereafter, in ${ }^{[14]}$ published the results of a 12 year follow-up of treated middle-aged hypertensive men and found a J-shaped relationship between systolic, as well as diastolic, blood-pressure and coronary heart disease. $\mathrm{In}^{[15]}$ reviewed 13 clinical trials and cohort studies with J-curve findings between DBP and cardiac events among treated participants with hypertension. They observed that the studies did not show a consistent $\mathrm{J}$ shaped relationship between treated blood pressure and stroke, but they did demonstrate a consistent J-shaped. In Norm tension the auto-regulatory mechanism is able to keep a stable milieu interior, i.e.: Maintain a plateau of blood flow into the brain within limits of 50 to 150 $\mathrm{mm} \mathrm{Hg}$ of mean arterial blood pressure. However, in hypertension, this curve shifts to the right and therefore caves in to a systemic drop in mean arterial pressure earlier than in a normotensive system creating grounds for ischemic cascade. Adapted from Chillon J.M. et al. 1997 relationship for cardiac events and DBP. The beneficial therapeutic threshold point was $85 \mathrm{~mm} \mathrm{Hg}$.

Explanatory mechanisms: Several mechanisms were used to explain the J-curve phenomenon in heart disease, most of which (other than the first point) would be applicable to cerebrovascular ischemic disease:

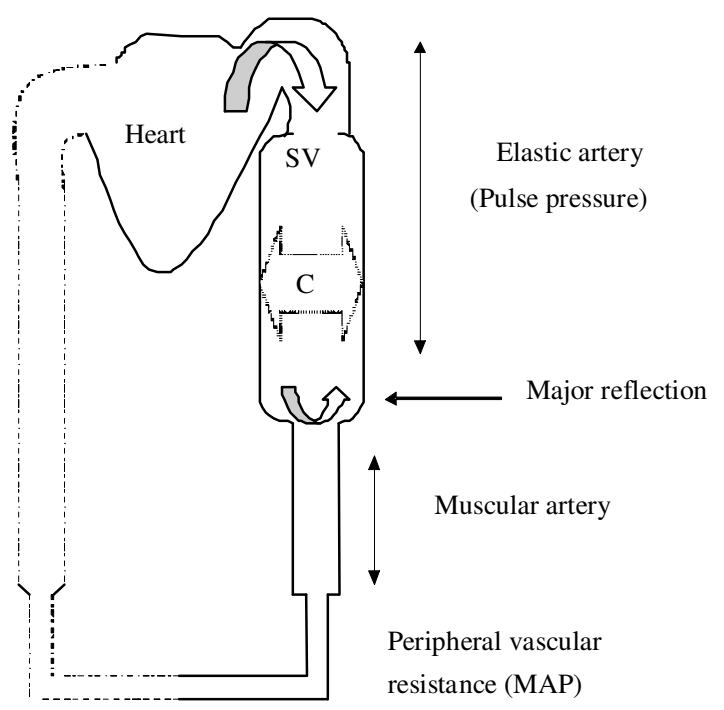

Fig. 1: Schema of pulse pressure ${ }^{\dagger}$ and mean arterial pressure, ${ }^{\dagger}$ Pulse pressure is determined by stroke volume, arterial compliance, and wave reflection as blood is pushed through the aortic tree. $\ddagger$ Mean arterial pressure is determined by cardiac output and peripheral vascular resistance, $\mathrm{C}=$ Arterial compliance $\mathrm{SV}=$ Stroke volume 
Hypertrophied ventricles, prevalent among hypertensives, have increased oxygen consumption and may become ischemic earlier than normal ventricles, smaller coronary vessels may not be able to dilate to regulate reduced blood flow, reduced DBP may lead to increased blood viscosity and platelet adhesiveness ${ }^{[15]}$, myocardial perfusion, which occurs mainly in diastole, will become critical at low DBP in patients with athermanous narrowing of the coronary arteries ${ }^{[16-18]}$.

The wide pulse pressure mechanism, focusing on people with isolated systolic hypertension was later introduced by ${ }^{[19]}$. A stiff aorta forces more of the heart's stroke volume into the periphery during systole, leaving less blood in the arterial tree during diastole, accounting for the higher systolic and lower diastolic pressure ${ }^{[20]}$ another theory postulates that pulse waves travel faster in older than in younger people. These pressure waves are reflected off the peripheral vascular resistance. With aging, the reflected waves travel faster and return to the central aorta in early to mid systole, where they augment the already elevated systolic blood-pressure (in younger people they return to the central aorta at the end of systole or early diastole and amplify the mean diastolic pressure ${ }^{[120,21]}$ (Fig. 1).

Auto regulation: In general, blood flow to vital organs of the body such as the heart, kidney and the brain, is normally auto-regulated, that is, within wide limits, blood flow remains constant within the organ in the face of changes in perfusion pressure. This ensures nutrients and oxygen supply. Auto-regulation is mediated by changes in the caliber of small arteries and arterioles. These vessels constrict when arterial bloodpressure rises and dilate when pressure falls (Fig. 2). This protective mechanism occurs within 15-30 sec while being driven by myogenic, metabolic and hormonal factors. However, below a certain pressure this mechanism begins to fail ${ }^{[18,22,23]}$.

Cerebral Auto regulation: Cerebral auto regulation was first described by ${ }^{[24]}$ and its existence in humans was established by ${ }^{[25]}$. Auto regulation in most circumstances does not determine the actual cerebral blood flow, rather, it insures constancy of the flow determined by nerve cell activity and changes in arterial carbon dioxide tension $^{[18]}$. In hypertension, vascular resistance is elevated in the brain, as elsewhere in the body, the arteriolar Lumina are narrowed and the walls thickened. This condition does not allow dilation of the arterioles in the face of systemic blood-pressure reduction $^{[26]}$.

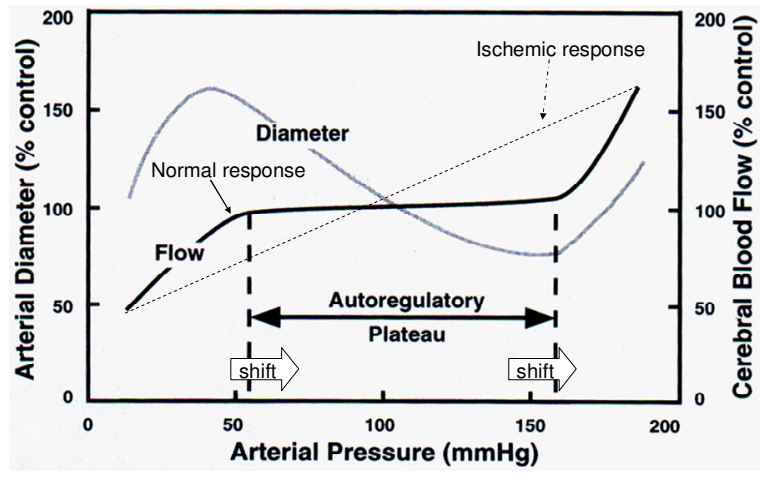

Fig. 2: Cerebral autoregulation, In Normotension the auto-regulatory mechanism is able to keep a stable milieu “interieur", i.e., Maintain a plateau of blood flow into the brain within limits of 50 to $150 \mathrm{mmHg}$ of mean arterial blood pressure. However, in hypertension, this curve shifts to the right and therefore caves in to a systemic drop in mean arterial pressure earlier than in a normotensive system creating grounds for ischemic cascade

Plausibility of the $\mathbf{j}$-curve in cerebrovascular disease: Just like in the coronary system, autoregulatory mechanisms control perfusion in the cerebrovascular system and are vulnerable to conditions such as arteriosclerosis and atherosclerosis. However, unlike in coronary heart disease, studies with findings of a J-curve between stroke and DBP appeared decades after Stewart's findings and so far, are fewer in number. One explanation for this discrepancy is that, unlike the coronary regulatory mechanism, the brain's compensatory system can increase oxygen extraction, when perfusion pressure falls below the limits of Auto regulation and can, therefore, better tolerate reductions in $\mathrm{DBP}^{[18]}$.

Nevertheless, it is plausible to consider a J-curve relationship between DBP and stroke, especially among older adults. Evidence exists that, in older persons and people with peripheral atherosclerosis, cuff DBP measures (disappearance of the Korotkoff sounds in phase V) are consistently higher than intra-arterial pressures by $10-15 \mathrm{~mm} \mathrm{Hg}^{[20]}$. Therefore the intraarterial brachial artery diastolic pressures are even lower than the "normal" or "low" measured values in such individuals, increasing their vulnerability to reduced DBP below the cerebral metabolic threshold ${ }^{[20]}$. In addition, cerebral metabolic rate, $\mathrm{Co} 2$ reactivity and blood flow velocity, decline with age ${ }^{[27]}$, rendering the brain more vulnerable to hypo perfusion than in younger individuals. Furthermore, hypertension-a condition most prevalent among older adults-shifts the 
cerebral auto-regulatory mechanism toward higher limits of blood-pressure, increasing the risk for homodynamic insufficiency when blood-pressure is reduced to levels considered normal for normotensive individuals (Fig. 3) ${ }^{[13,28,29]}$.

A study was conducted to evaluate cerebral Auto regulation in 8 patients hospitalized for malignant hypertension and 8 normotensive controls. Middle cerebral artery blood velocity and blood pressure were monitored. During 90 minutes of acute blood-pressure reduction, middle cerebral artery blood velocity decreased almost one on one with mean arterial bloodpressure decrease among the hypertensive patients, indicating impaired cerebral Auto regulation ${ }^{[29]}$.

The (short) history of the $\mathbf{j}$-curve in stroke events:

Table 1 summarizes the various studies with a finding of a J-shaped relationship between bloodpressure and stroke. Shortly after reporting the finding in 1987 of increasing ischemic heart disease, when reducing DBP below a threshold of $85 \mathrm{~mm} \mathrm{Hg}^{[30]}$ addressed the question of $\mathrm{J}$-shaped relationship of blood-pressure and stroke in a subgroup analysis of a 10 year follow-up data on blood-pressure reduction in hypertensive individuals, comparing the use of betablockers with other anti-hypertensive treatments. Twenty one deaths occurred due to stroke among the 902 participants, most of them over age 59. A J-shaped pattern existed between systolic blood-pressure and stroke mortality. The optimal systolic blood-pressure was $139-142 \mathrm{~mm} \mathrm{Hg}$, where only one stroke death occurred in 301 subjects. There were 9 stroke deaths in the lower tactile (below $139 \mathrm{~mm} \mathrm{Hg}, \mathrm{n}=301$ ) and 11 deaths in the 300 participants with systolic bloodpressure above $142 \mathrm{~mm} \mathrm{Hg}$.

In 1990 al-Roomi et al. ${ }^{[40]}$ \{al Roomi, 19901092 /id \} published the results of a population-based casecontrol study to determine the relationship between hypertension and its treatment on cardiovascular outcomes in persons aged 35-69 years in the Hunter Region, Great Britain. Patients with a first episode of AMI or stroke were identified from community-based heart attack and stroke registers and compared with control subjects obtained from a random population sample from the same community. Those with a treated diastolic blood pressure of less than $80 \mathrm{~mm} \mathrm{Hg}$ appeared to be at a higher risk of both AMI and stroke than those with a treated diastolic blood pressure level of $80-89 \mathrm{~mm} \mathrm{Hg}$, but the difference was not statistically significant.

In 1992 Selmer $^{[41]} \quad$ SSelmer, $\left.1992 \quad 657 / \mathrm{id}\right\}$ published results from her survey on blood pressure carried out in Bergen, Norway. Baseline information was recorded in 1963 and participants, 30 to 89 years of age totaling 52,064, were followed up for 20 years for mortality. Stroke mortality rates tended to have a Jshape among men 50-79 years of age (model's quadratic term $\mathrm{p}=0.003$ ) and among women 70-89 years of age (model's quadratic term $\mathrm{p}=0.002$ ).

In 1996 Manolio et al. ${ }^{[42]}$ \{Manolio, 1996 777/id\} published the results of a prospective study of 5201 participants aged 65 years and older from the Cardiovascular Health Study looking for precursors of stroke. Stratification by systolic-pressure quintile among users of antihypertensive medications suggested an increased risk of stroke in systolic blood pressure $\leq 127 \mathrm{~mm} \mathrm{Hg}$ (HR $=0.76,95 \% \mathrm{CI}, 0.421 .37)$ compared with the next higher quintile of $128-140 \mathrm{~mm} \mathrm{Hg}$ (reference category).

$\mathrm{In}^{[31]}$ studied the relationship between post-stroke DBP and recurring stroke. They recruited and followed 368 patients who were admitted to the same hospital in Japan within 3 months of their initial stroke onset. Mean follow-up time was 38 months and mean age of participants was 62. Baseline blood-pressure was determined 4 weeks after the occurrence of stroke. Any blood-pressure measurement after baseline was considered to be post stroke blood-pressure. Dividing mean post stroke DBP into tertiles, the investigators reported a J-shaped relationship between diastolic blood-pressure and recurring stroke, controlling for baseline blood pressure, age and hypertension treatment. Patients with DBP of $80-84 \mathrm{~mm} \mathrm{Hg}$ had the lowest stroke recurrence rate (3.8\%/patient year). Both, diastolic blood-pressure below $80 \mathrm{~mm} \mathrm{Hg}(9.2 \% /$ patient year, $\mathrm{p}<0.05)$ and above $89 \mathrm{~mm} \mathrm{Hg}(11.4 \% /$ patient year, $\mathrm{p}=0.01$ ) were associated with a higher risk of recurring stroke.

During the 1980's and the 1990's, two clinical trials tried to shed more light on the question of the Jcurve between blood pressure and cardiovascular events. The BBB multi-center study (Swedish acronym for Treat Blood-Pressure Better) ${ }^{[32,33]}$ looked at the effect of intensified antihypertensive treatment on the level of blood-pressure and morbidity and mortality in treated hypertensive patients aged 46-71 years, that were under what was considered good control of hypertension. Inclusion DBP range was 90-100 mm Hg. Participants were randomized to intensified and customary hypertension treatment. For about 4 years the mean maintained DBP in the intensified treatment group was $83 \mathrm{~mm} \mathrm{Hg}$ compared to $91 \mathrm{~mm} \mathrm{Hg}$ in the usual treatment group. No differences in morbidity or mortality were identified between the two groups (28/1057 vs. $29 / 1070$ strokes and MI's and 8/1057 and $11 / 1070$ strokes in intensified vs. customary treatment) 
and no J-curves were demonstrated. The conclusion was that intensive lowering of DBP (to $83 \mathrm{~mm} \mathrm{Hg}$ ) was safe and the null outcome may be due to the small number of participants. They suggested that a larger study was needed to answer the question of the benefit of intensified treatment, which paved the way for the HOT trial.

The Hypertension Optimal Treatment $(\text { HOT })^{[34,35]}$ randomized trial was set to assess the optimal target DBP to prevent cardiovascular events in 18,790 hypertensive individuals 50-80 years of age with DBP between 100 and 115 (mean 105) mm Hg. Participants were assigned to 3 target DBP groups: below 90, below 85 and below $80 \mathrm{~mm} \mathrm{Hg}$. DBP was reduced by 20.3 , 22.3 and $24.3 \mathrm{~mm} \mathrm{Hg}$ respectively. The small difference in the blood pressure reduction between the 3 target groups made it difficult to recognize significant differences in event rates between them. Stroke event rates per 1000 patient years were similar (4, 4.7 and 3.8 respectively, $\mathrm{P}$ for trend $=0.74)$. When results of the HOT study were analyzed as a function of achieved diastolic blood-pressure, the lowest risk for stroke (4 events/1000 person years, $\mathrm{CI}=3,5$ ) was at DBP below $80 \mathrm{~mm} \mathrm{Hg}$ (down to $70 \mathrm{~mm} \mathrm{Hg}$ ). No information was available at DBP below $70 \mathrm{~mm} \mathrm{Hg}$. A non-significant increase (from 3.5-5.5/1000 PY) in cardiovascular deaths (J-curve) was identified at the lowest achieved level of DBP (around $70 \mathrm{~mm} \mathrm{Hg}$ ). No definite answer was therefore provided by the HOT study with regard to the J-shape phenomenon. The conclusion was that lowering DBP below $85 \mathrm{~mm} \mathrm{Hg}$ (down to $70 \mathrm{~mm} \mathrm{Hg}$ ) appears to give little benefit.

One possible implication of the results of the $\mathrm{BBB}$ and HOT studies is that if the J-curve exists, it may appear in blood-pressure levels below those demonstrated by the two studies (70 and $83 \mathrm{~mm} \mathrm{Hg}$ ). Such blood-pressure levels are more likely to occur in the real world of the general population and less likely to surface in a controlled clinical trial.

In view of the non-definitive outcomes in the BBB and HOT trials ${ }^{[36]}$ conducted the first observational study, specifically designed to answer the question of whether stroke-risk continued to decrease with decreasing blood-pressure. The results were published in 1999. The investigators followed older adults within the Rotterdam Study, a population-based cohort. Baseline information was collected in 1990 when 6,927 participants, 55 years of age and older, were recruited and followed for incident stroke during an average of 4.7 years. Hypertension was defined as systolic bloodpressure $>160$, or DBP $>95$, or use of antihypertensive treatment.

Using a Cox regression model and controlling for age, gender, smoking habits, diabetes mellitus, ankle- arm index, myocardial infarction, arterial fibrillation, intermittent claudication, angina pectoris and TIA, the investigators compared treated and non-treated hypertensive for the risk of incident stroke. They observed a linear relationship between increasing DBPas well as increasing systolic blood-pressure-and incident stroke, among non-treated subjects. A J-shaped relationship was demonstrated between systolic bloodpressure-as well as diastolic blood-pressure-and incident stroke among treated hypertensive. The left arm of the J-curve was statistically significant only in $\mathrm{DBP}(\mathrm{RR}=1.8, \mathrm{CI}=1.05,3.1)$, when compared to the (second) optimal blood-pressure quartile of $65-74 \mathrm{~mm}$ $\mathrm{Hg}$. The risk in the highest (fourth) quartile of DBP (>84 mm Hg) was $1.7(\mathrm{CI}=1,3.1)$. The shape of this relationship did not change substantially after excluding individuals with isolated systolic hypertension, or subjects with history of myocardial infarction, from the analysis, or after controlling for systolic blood-pressure. Though wide pulse pressure could partially explain the J-shape findings (mostly in people with isolated systolic hypertension), the investigators suggested the shift to the right in the cerebral auto-regulatory mechanism as a plausible explanation. This, however, did not explain why the threshold of risk would occur only among treated hypertensive and why spontaneously occurring low blood-pressure was beneficial. The investigators did not have the means to investigate to what extent the low blood-pressure among treated subjects was due to the treatment itself, but cautioned about reducing DBP among treated hypertensive individuals below $80 \mathrm{~mm}$ $\mathrm{Hg}$.

In a letter to the editor about these findings ${ }^{[37]}$ suggested looking at the risk of stroke by pulse pressure categories. The authors replied that there was no difference in risk between the reference and the highest category of pulse pressure among treated subjects. Fournier et $a l^{[38]}$ suggested that some hypertension treatments such as ACE and $\beta$-blockers are less effective against stroke compared to diuretics. The authors responded that the differences in antihypertensive drug use were not large between the four DBP categories. Voko et al. ${ }^{[36]}$ also added that they suggested a DBP of $80 \mathrm{~mm} \mathrm{Hg}$ as the limit for bloodpressure lowering and not 75 (the higher limit of the optimal category), since that is the limit which is practiced clinically.

During the same year, Somes et al. ${ }^{[7]}$ reanalyzed the data from the SHEP placebo controlled clinical trial, in 4,736 people 60 years of age and older with isolated systolic hypertension. Using a Cox regression analysis, they found that, in the placebo group, a $5 \mathrm{~mm} \mathrm{Hg}$ decrease in DBP was associated with an $8 \%(\mathrm{RR}=$ $0.92, \mathrm{CI}=0.85,1)$ reduction in the risk of stroke. 
Am. J. Pharm. \& Toxicol., 3 (1): 185-192, 2008

Table 1: Summary of longitudinal studies with a finding of J-curve or studies in search of a J-curve relationship between blood-pressure and stroke

\begin{tabular}{|c|c|c|c|c|c|c|c|c|c|c|}
\hline Author & Study name & $\begin{array}{l}\text { Public } \\
\text { year }\end{array}$ & $\begin{array}{l}\text { Study } \\
\text { type }\end{array}$ & $\begin{array}{l}\text { Sample } \\
\text { size }\end{array}$ & Age & Outcome & $\begin{array}{l}\text { DBP criteria for } \\
\text { inclusion }(\mathrm{mm} \mathrm{Hg})\end{array}$ & $\begin{array}{l}\text { Optimal BP } \\
(\mathrm{mm} \mathrm{Hg})\end{array}$ & Analysis & $\begin{array}{l}\text { Results (lowest to } \\
\text { highest BP category } \\
\text { (mmHg) }\end{array}$ \\
\hline Cruickshank & Clatterbridge & 1987 & $\begin{array}{l}\text { CT (Rx vs. } \\
\text { placebo) }\end{array}$ & 902 & $>60$ & $\begin{array}{l}\text { Stroke } \\
\text { mortality }\end{array}$ & $>90$ & $\begin{array}{l}85-90 \\
139-142\end{array}$ & Subgroup & $\begin{array}{l}\text { category }(\mathrm{mm} \mathrm{Hg}) \\
\dagger \text { By tertiles: } 9 / 301, \\
1 / 301,11 / 300\end{array}$ \\
\hline Irie & $\begin{array}{l}\text { National } \\
\text { cardiovascular } \\
\text { center (Japan) }\end{array}$ & 1993 & $\begin{array}{l}\text { Hospital } \\
\text { Cohort }\end{array}$ & 368 & 62 (mean) & $\begin{array}{l}\text { Recurring } \\
\text { stroke }\end{array}$ & $\begin{array}{l}\text { All (within } 3 \\
\text { months months } \\
\text { of } 1^{\text {st }} \text { stroke) }\end{array}$ & $80-84$ & Main & $\begin{array}{l}\dagger \text { By tertiles: } 9 / 301 \text {, } \\
1 / 301,11 / 300\end{array}$ \\
\hline Hansson & $\mathrm{BBB}$ & 1994 & $\begin{array}{l}\text { CT }(2 \mathrm{Rx} \\
\text { intensities })\end{array}$ & 1985 & $46-71$ & $\begin{array}{l}\text { Stroke in } \\
\text { intensified vs. } \\
\text { customary } \\
\text { treatment }\end{array}$ & $90-100$ & $\begin{array}{l}\text { 83-91 No } \\
\text { J-shape }\end{array}$ & $\begin{array}{l}\text { Subgroup } \\
\text { above } \sim 75\end{array}$ & $\begin{array}{l}\text { Similar incidence: } \\
8 / 1057 \text { patients in } \\
\text { achieved DBP of } 83 \text {, } \\
11 / 1070 \text { patients in } \\
\text { achieved DBP of } 91\end{array}$ \\
\hline Hansson & HOT & 1998 & $\begin{array}{l}\text { CT ( } 3 \mathrm{Rx} \\
\text { intensities) }\end{array}$ & 18,790 & $50-80$ & $\begin{array}{l}\text { Stroke in } \\
\text { achieved DBP } \\
<90,<85,<80\end{array}$ & $\begin{array}{l}100-115 \\
\text { shape above } 70\end{array}$ & $\begin{array}{l}70-80 \text { No J- } \\
\text { per } 1000 \text { PY: }\end{array}$ & $\begin{array}{l}\text { Subgroup } \\
4,4.7,3.8\end{array}$ & No difference in rates \\
\hline Voko & Rotterdam & 1999 & $\begin{array}{c}\text { Cohort }(\mathrm{Rx} \\
\text { vs. no } \mathrm{Rx})\end{array}$ & 6,927 & $>55$ & Stroke & $>95$ & $65-74$ & Main & $\begin{array}{l}4,4.7,3.8 \\
\dagger R R \text { in treated: } \\
<6=1.8 \\
65-74=1 \\
75-84=1.4 \\
>84=1.7\end{array}$ \\
\hline Somes & SHEP & 1999 & $\begin{array}{l}\text { CT (Rx vs. } \\
\text { placebo in ISH }\end{array}$ & $\begin{array}{l}4736 \\
\text { I) }\end{array}$ & $>60$ & CVD & $<90$ & 75 & Re-analysis & $\begin{array}{l}\text { Threshold for CVD } \\
\text { in treated at } 70(\mathrm{RR}= \\
1.3) \text { compared to } 75\end{array}$ \\
\hline Kario & -- & 2001 & Cohort & 575 & $\begin{array}{l}\text { Older } \\
\text { adults }\end{array}$ & Stroke & $>80$ (ambulatory) & $\begin{array}{l}\text { Normal } \\
\text { dipping }\end{array}$ & Main & $\begin{array}{l}\dagger \mathrm{RR}: \text { Extreme } \\
\text { dippers }=2.38 \\
\text { Normal }=1, \text { Reverse } \\
\text { Dippers }=1.93\end{array}$ \\
\hline
\end{tabular}

However, the same reduction in DBP among actively treated subjects was associated with increase in the risk of stroke ( $\mathrm{RR}=1.14$ per $5 \mathrm{~mm} \mathrm{Hg}$ decrease, $\mathrm{CI}=1.05$, 1.22). The baseline risk of age, sex and race, as well as previous intake of hypertension treatment, diabetes and previous heart attack or stroke were held constant. Systolic and diastolic blood-pressures were entered into the model as time dependent variables. When looking at CVD risk, there was a significant threshold for increased relative risk at DBP of $70 \mathrm{~mm} \mathrm{Hg}(\mathrm{RR}=1.3$, $\mathrm{CI}=1,1.6$ ) compared to $75 \mathrm{~mm} \mathrm{Hg}$ among the treated. The risk continued to increase with decreasing DBP, reaching 2.2 at DBP of $40 \mathrm{~mm} \mathrm{Hg}$. This association persisted when stratifying by pulse pressure tertiles and the findings, therefore, could not be attributed solely to increased arterial stiffness. This effect was specific: No increase in risk was observed in non-CVD events and cancer with decreasing DBP. This led the investigators to conclude that DBP, among some treated hypertensives, may be reduced to levels that uncover sub clinical disease, or that some individuals are being over treated. They suggested more careful titration of antihypertensive therapy.

In 2001, Kario et al. ${ }^{[39]}$ reported the results of a study on the relationship between nocturnal bloodpressure and incident stroke. They followed 575 elderly Japanese patients with hypertension for a 20 month period between 1996 and 1998. The inclusion criteria were: average clinic systolic blood-pressure $>140 \mathrm{~mm}$ $\mathrm{Hg}$ or average DBP $>90 \mathrm{~mm} \mathrm{Hg}$ on more than 2 occasions, average 24 hour ambulatory systolic bloodpressure $>130 \mathrm{~mm} \mathrm{Hg}$ or average ambulatory DBP $>80$ $\mathrm{mm} \mathrm{Hg}$, age $>50$ years and no intake of hypertension treatment 14 days prior to the ambulatory bloodpressure measurement. Participants were classified by nocturnal blood-pressure fall (dipping) status: 10-20\% $=$ normal, $0-10 \%=$ non-dippers, $>20 \%=$ dippers, $<0 \%$ $=$ reverse dippers. $\mathrm{A} \mathrm{J}$-shaped relationship was demonstrated between the 54 stroke events and crude dipping status (extreme $\mathrm{D}=12 \%$, normal $=0.06 \%$, non $\mathrm{D}=0.08 \%$, reverse $\mathrm{D}=22 \%, \chi^{2} \mathrm{p}=0.001$ ) after controlling, via a Cox regression analysis, for age, gender, 24 hour systolic blood-pressure, body-mass index, diabetes, hyperlipidemia, current smoking and reported hypertension treatment, the relationship became U-shaped with the highest risk expressed among the extreme dippers. The RR's, using normal as the reference category, were: Extreme $\mathrm{D}=2.38$, normal $=1$, non- $\mathrm{D}=0.98$ and reverse $\mathrm{D}=1.93$. The authors concluded that in older Japanese hypertensive patients, extreme dipping nocturnal blood pressure may be related to silent and clinical cerebral ischemia. The suggested explanatory mechanism was hypo-perfusion during sleep.

\section{DISCUSSION}

Studies reporting a J-shaped relationship between a blood pressure index level and stroke morbidity or mortality demonstrated significant associations mostly with DBPlevels and not with systolic blood-pressure 
levels. The optimal diastolic blood-pressure for stroke prevention ranged between 65 and $85 \mathrm{~mm} \mathrm{Hg}$ and the $\mathrm{J}$ curve findings between a stroke outcome and bloodpressure were reported mostly in observational studies.

The studies depicting a J-curve relationship between blood-pressure and stroke were fewer than those associating ischemic heart disease with such a phenomenon and appeared later chronologically. Yet, they may provide evidence, that in certain populations, such as older adults, or hypertensives and possibly others with a vulnerable cardiovascular system, a threshold for lowering blood-pressure may exist and may warrant consideration and caution in order to insure adequate cerebral perfusion and prevent stroke. While subclinical disease was suggested as an explanation for the J-shape phenomenon in the studied populations, mechanisms involving hemodynamic effects such as reduced perfusion to the heart or brain, wide pulse pressure, sluggish autoregulatory mechanisms of blood flow were also proposed. These explanations are plausible since the same mechanisms could also be vulnerable to the effects of hypertension and aging on the vascular system. These explanations would therefore warrant studying the optimal blood pressure level to minimize stroke specifically in older hypertensive populations.

The main limitations of the reported studies as they pertain to the relationship between blood pressure level and stroke are: Some were not designed a priori to answer this question and reported a subgroup analysis; most or all studies did not differentiate between ischemic and hemorrhagic strokes, even though the mechanisms of these two outcomes may differ; and a number of the observational studies did not account for important covariates such as age, gender, smoking, weight, co-morbidities, years of hypertension exposure, and hypertension treatment,

\section{CONCLUSION}

In certain populations, such as older adults, or hypertensives, a threshold for lowering blood-pressure may exist and may warrant consideration in order to insure adequate cerebral perfusion and ischemic stroke prevention. Several studies have demonstrated a Jshaped relationship between DBP and stroke. The optimal diastolic blood-pressure for stroke-risk reduction ranged between 65 and $85 \mathrm{~mm} \mathrm{Hg}$. DBP levels below (as well as above) that range were associated with increased risk. The findings varied by outcome (stroke mortality/morbidity), gender, age, hypertension status, and hypertension treatment status. The optimal blood-pressure level to reduce the risk of stroke needs further research, is yet to be determined, and may be specific to vulnerable populations such as older adults or people with hypertension.

\section{REFERENCES}

1. Holmes, F.L., C. Bernard, 1986. The milieu interieur, and regulatory physiology. Hist. Philos. Life Sci., 8: 3-25.

2. Carruthers, S.G., 1992. The J-curve-it is clinically relevant? Can. J. Cardiol., 8: 563.

3. Fineberg, M., 1927. Systolic hypertension: Its relationship to atherosclerosis of the aorta and larger arteries. Am. J. Med. Sci., 8: 35-843.

4. Ramsay, L.E., 1986. Waller PC. Strokes in mild hypertension: Diastolic rules. Lancet, 2: 854-856.

5. Kaplan, N.M., 2002. Kaplan's Clinical Hypertension. Lippincott Williams and Wilkins.

6. Staessen, J.A., Gasowski, J., J.G. Wang, L. Thijs, E. Den Hond, J.P. Boissel, J. Coope, T. Ekbom, F. Gueyffier, L. Liu, K. Kerlikowske, S. Pocock and R.H. Fagard, 2000. Risks of untreated and treated isolated systolic hypertension in the elderly: Metaanalysis of outcome trials. Lancet.355: 865-872.

7. Somes, G.W., M. Pahor, R.I. Shorr, W.C. Cushman and W.B. Applegate.1999. The role of diastolic blood pressure when treating isolated systolic hypertension. Arch. Intern. Med., 159: 2004-2009.

8. Stewart, I.M., 1979. Relation of reduction in pressure to first myocardial infarction in patients receiving treatment for severe hypertension. Lancet, 1: 861-865.

9. Lew, E.A., 1973. High blood pressure, other risk factors and longevity: The insurance viewpoint. Am. J. Med., 55: 281-294.

10. Zanchetti, A., A. Amery, G. Berglund, J.M. Cruickshank, L. Hansson, A.F. Lever and P. Sleight. 1989. How much should blood pressure be lowered? The problem of the J-shaped curve. J. Hypertens Suppl., 7: S338-S348.

11. Anderson, T.W., 1978. Re-examination of some of the Framingham blood-pressure data. Lancet, 2: $1139-1141$.

12. Cruickshank, J.M., J.M. Thorp and F.J. Zacharias, 1987. Benefits and potential harm of lowering high blood pressure. Lancet. 1: 581-584.

13. Onrot, J., 1993. Hypertension and the J-curve. How low should you go? Can. Fam. Physician, 39: 1939-1943.

14. Samuelsson, O.G.,L.W.Wilhelmsen, K.M. Pennert, H. Wede and G.L. Berglund, 1990. The J-shaped relationship between coronary heart disease and achieved blood pressure level in treated hypertension: Further analyses of 12 years of follow-up of treated hypertensives in the primary prevention trial in Gothenburg, Sweden. J. Hypertens, 8: 547-555.

15. Farnett L, C.D. Mulrow, W.D. Linn, C.R. Lucey and M.R. Tuley, 1991.The J-curve phenomenon and the treatment of hypertension. Is there a point beyond which pressure reduction is dangerous? JAMA. 265: 489-495. 
16. Green, K.G., The role of hypertension and downward changes of blood pressure in the genesis of coronary atherosclerosis and acute myocardial ischemic attacks. Am. Heart J.,103: 579-582.

17. Green, K.G., 1972. Optimised blood-pressure. Lancet, 2: 33.

18. Strandgaard, S., S. Haunso, 1987. Why does antihypertensive treatment prevent stroke but not myocardial infarction? Lancet, 2: 658-661.

19. Kannel, W.B., P.W. Wilson, B.H. Nam, R.B. D'Agostino and J. Li, 2004. A likely explanation for the J-curve of blood pressure cardiovascular risk. Am. J. Cardiol., 94: 380-384.

20. Smulyan, H., M.E. Safar, 2000. The diastolic blood pressure in systolic hypertension. Ann. Intern. Med., 132: 233-237.

21. Art, A.M., B.A. Kingwell, 2001. Pulse pressure-a review of mechanisms and clinical relevance. J. Am. Coll. Cardiol. 37: 975-984.

22. Cruickshank, J.M., 1994. J curve in antihypertensive therapy-does it exist? A personal point of view. Cardiovasc Drugs Ther, 8: 757-760.

23. Cruickshank, J.M., 1992. The role of coronary perfusion pressure. Eur. Heart J., 13: 39-43.

24. Fog, M., Cerebral circulation: the reaction of the pial arteries to fall in blood pressure. Arch Neurol Psychiatr 937; 351-364.

25. Lassen, N.A., 1959. Cerebral blood flow and oxygen consumption in man. Physiol. Rev., 39: 183-238.

26. Barry, D.I., J.O. Jarden, O.B. Paulson, D.I. Graham and S. Strandgaard, 1984. Cerebrovascular aspects of converting-enzyme inhibition I: Effects of intravenous captopril in spontaneously hypertensive and normotensive rats. J. Hypertens. 2: 589-597.

27. Bakker, S.L., F.E. de Leeuw, T. den Heijer, P.J. Koudstaal, A. Hofman and M.M. Breteler, 2004. Cerebral haemodynamics in the elderly: The rotterdam study. Neuroepidemiology. 23: 178-184.

28. Strandgaard, S., O.B. Paulson, 1989. Cerebral blood flow and its pathophysiology in hypertension. Am. J. Hypertens. 2: 486-492.

29. Immink, R.V., van den B.J. Born, G.A. van Montfrans, R.P. Koopmans, J.M. Karemaker and J.J. van Lieshout, 2004. Impaired cerebral Auto regulation in patients with malignant hypertension. Circulation, 110: 2241-2245.

30. Cruickshank, J.M., T.J. Higgins, K. Pennert, J.M. Thorp, F.M. Zacharias and F.J. Zacharias, 1987. The efficacy and tolerability of antihypertensive treatment based on atenolol in the prevention of stroke and the regression of left ventricular hypertrophy. J. Hum. Hypertens, 1: 87-93.
31. Irie, K., T. Yamaguchi, K. Minematsu and T. Omae, 1993. The J-curve phenomenon in stroke recurrence. Stroke, 24: 1844-1849.

32. Hannson, L., 1988. The BBB Study: The effect of intensified antihypertensive treatment on the level of blood pressure, side-effects, morbidity and mortality in well-treated hypertensive patients. Behandla Blodtryck Battre., 3: 248-254.

33. The BBB study: A prospective randomized study of intensified antihypertensive treatment. The BBB study group. J. Hypertens, 6: 693-697.

34. Hansson, L., A. Zanchetti, S.G. Carruthers, B. Dahlof, D. Elmfeldt, S. Julius, J. Menard, K.H. Rahn, H. Wedel and S. Westerling, 1998. Effects of intensive blood-pressure lowering and low-dose aspirin in patients with hypertension: Principal results of the Hypertension Optimal Treatment (HOT) randomised trial. HOT Study Group. Lancet, 351: 1755-1762.

35. Leonetti, G. and A. Zanchetti, 1992. Principal results of Hypertension Optimal Treatment (HOT) study and their clinical impact. HOT cooperative group. Clin. Hemorheol Microcirc., 21: 217-224.

36. Voko, Z., M.L. Bots, A. Hofman, P.J. Koudstaal, J.C. Witteman and M.M. Breteler, 1999. J-shaped relation between blood pressure and stroke in treated hypertensives. Hypertension, 34: 1181-1185.

37. Verdecchia, P., G. Schillaci, O.R. Silvestrini, 2000. J-shaped relation between blood pressure and stroke. Hypertension, 35: E15.

38. Fournier, A., H. Mazouz, R. Oprisiu, A. Pruna, J.M. Achard and L. Fernandez, 2000. J-shaped relation between blood pressure and stroke. Hypertension, 35: E16.

39. Kario, K., T.G. Pickering, T. Matsuo, S. Hoshide, J.E. Schwartz and K. Shimada, 2001. Stroke prognosis and abnormal nocturnal blood pressure falls in older hypertensives. Hypertension, 38: 852-857.

40. Al Roomi, K.A., R.F., Heller and J. Wlodarczyk, 1990. Hypertension control and the risk of myocardial infarction and stroke: A populationbased study. Med. J. Aust., 153: 595-3.

41. Selmer, R., 1992. Blood pressure and twenty-year mortality in the city of Bergen. Norway. Am. J. Epidemiol. 136: 428-440.

42. Manolio, T.A., R.A. Kronmal, G.L. Burke, D.H. O'Leary and T.R. 1996. Price short-term predictors of incident stroke in older adults. The Cardiovascular Health Study Stroke, 27: 14791486. 